\title{
Effect of Organizational Justice on Affective Organizational Commitment: Mediating Role of Perceived Organizational Support
}

\author{
Li Song, Li Yang* \\ Email address: \\ lilysong23@163.com (Li Song), 1468507309@qq.com (Li Yang) \\ ${ }^{*}$ Corresponding author
}

School of Economics and Management, Anhui University of Science and Technology, Huainan, China

To cite this article:

Li Song, Li Yang. Effect of Organizational Justice on Affective Organizational Commitment: Mediating Role of Perceived Organizational Support. Psychology and Behavioral Sciences. Vol. 9, No. 5, 2020, pp. 61-67. doi: 10.11648/j.pbs.20200905.11

Received: August 3, 2020; Accepted: September 21, 2020; Published: September 28, 2020

\begin{abstract}
Background: Employees' affective commitment is helpful to get high performence and build competitiv advantage for a company. How to enhance employees' affective commitment is a hot topic in the field of management. In this study, we explore the relationship between affective commitment, perceived organizational support and job involvement. Methods: We surveyed 217 employees from local companies. We used analysis of Pearson correlation and regression models to explore associations between affective commitment, perceived organizational support and job involvement. Results: We found organiztional justice has a significant positive effect both on emplyees' perceived organizational support and affective commitment, especially procedural justice is the most important variant effecting employees' perceived organizational support, and leadership justice is the most significant variant influencing affective commitment, perceived organizational support plays a partial mediating role between organizational justice and job involvement. Conclusions: Findings suggest that individual perception of the organizational support plays a role in understanding when and why employees pay high attention to their work and invest more effort to achieve organizational goals. It is critical to cultivate employees' affective commitment to their organization by method of creating a fair and supportive internal culture, which focus on procedural justice and consistently supportive organizational policies.
\end{abstract}

Keywords: Organizational Justice, Perceived Organizational Support, Affective Commitment

\section{Introduction}

In fierce market environment, the competitive advantages of a company obtained by capital, technology and other resources are easy to be imitated by competitors. However, due to the strong background and path dependence of knowledge and ability, human resource is one of the most important strategic factors for a company to keep competitive advantage. The success or failure of an enterprise directly depends on the quality and performance of its employees. In recent years, increased attention has been given to affective organizational commitment which is a critical factor for employees' work performance [1]. How to enhance employees' affective organizational commitment is a hot topic in the field of management [2]. Organizational justice deals with understanding the complexity of fair treatment in a work setting, which is reflected in the classic prescripts of justice. Individuals' sense of organizational justice can significantly affect their work attitude to the organization [3]. On this basis, this study makes a survey to explore the psychological mechanism of affective commitment from organizational justice perspective.

\section{Literature Review}

\subsection{Affective Organizational Commitment}

Organizational commitment is the general emotional response of employees to the organization as a whole, which is usually expressed as an emotional dependence of employees on the organization [4]. Employees are reluctant to leave a enterprise not because of losing benefits such as pension, but because of their emotional dependence on the 
organization [5]. Many researchers have studied composition of organizational commitment and put forward different thoeries and composition list. For example, according to the three-component model of organizational commitment (TCM), there are three kinds of organizaional commitment: affective organizational commitment (AOC), continuance organizational commitment (COC) and normative organizational commitment (NOC) [6]. AOC is described as the degree of employees' identification with the organization, which is based on a sense of shared values with, and features a strong emotional attachment to, the organization and as such is the commitment component that most strongly fosters the desire to contribute to the organization's success. COC is the requirement of employees to work continuously for the organization, which is a cumulative dimension. NOC refers to the employees' sense of responsibility to the organization, including the accumulated sense of responsibility on individuals and the constraints of social norms. In short, people stay in an organization because they are willing (affective), need (continuous), or feel they should be (normalized). The TCM model has been cited extensively and has become the mainstream in organizational commitment research [7]. According to the five-component model of organizational commitment, organizational commitment is divided into five categaries: affective organizational commitment (AOC), normative organizational commitment (NOC), ideal organizational commitment (IOC), opportunity organizational commitment (OOC) and economic organizational commitment (EOC). AOC is the deep feelings with the enterprises. IOC means that employees attach importance to personal growth and pursue the realization of their ideals. Therefore, employees are very concerned about whether their own expertise can provide various working conditions, learning and promotion opportunities, so as to realize their ideals. NOC describes employees' attitude and behavior towards the enterprise which based on social norms and professional ethics, that is to say, employees have a sense of responsibility for the organization. EOC refers to the fact that employees stay in the company because they will suffer economic losses if they leave. OOC means that employees stay in the enterprise just because they have no opportunity to find another job. Many stuies have proved that organizational commitment is quite stable and consistent [8]. Especially, Employees with a sense of affective commitment will increase their loyalty to the enterprise and are more likely to engage in extra role activities such as creation and innovation. The affective commitment of employees to the organization is influenced by individual needs and their expectations of the organization, as well as the actual satisfaction they feel. Organizational reliability is an important factor affecting employees' emotional commitment [9].

\subsection{Organizational Justice}

Organizational justice is concerned with perceptions of fairness in the workplace [10]. In the process of social exchange, the employee compares the reward paid to the rate of contribution to others, and the individual will be fair when the individual is equal to the contribution made by others. Employees are more likely to demonstrate positive work attitudes and behaviors when they perceive the organization and authority figures as fair. Conversely, when employees feel they have not been treated fairly in work-related matters, they are more likely to respond with anger, resentment and retaliatory behaviors [11]. At early stage, organizational justice is one-dimensional, only refers to the degree to which rewards and punishments are related to performance inputs, that is distributive justice. Later procedural justice was found to be included, which is based on judgments of fairness regarding the policies and procedures used in the decision making process of organizations [12]. Bies \& Moag (1986) [13] suggests that organizational justice consists of distributive justice, procedure justice and interactive justice; there into, interactive justice is primarily concerned with the extent to which employees perceive their respect. Greenberg (1993) [14] divided interactive justice into interpersonal justice and information justice. Interpersonal justice refers to quality of interpersonal treatment received during the enactment of organizational procedures. Informational justice is based on the degree of explanation provided to employees regarding distribution of outcomes and the procedures used to make these determinations. Colquitt (2013) [15] divided organizational justice into four dimensions including distributive justice, procedural justice, interpersonal justice and informational justice. Thereinto, distributive justice is the sense of fairness that employees perceive to pay or other decisions; procedural justice focus on fairness of the communication and the implementation process, while interpersonal justice emphasis the extent that employees feel that they are respected and concerned. Chong-ming Wang (2001) [16] divided organizational justice into four dimensions including distributive justice, procedural justice, leadership equity and informational justice based on mass social survey in China, there into, distributive justice refers to perception of the staff on resource allocation fairness of the organization, especially compensation distribution. Procedural justice refers to perception of execution process fairness; leadership justice refers to perception concern and respect of supervisors on the staff. Information justice refers to the perception that supervisors give full explanation to the staff in the organization's affairs.

\subsection{Perceived Organizational Support}

Perceived organizational support (POS) is defined as global beliefs developed by employees' concerning the extent to which the organization values their contributions and cares about their well-being [17]. By empirical study on Chinese employees, Wen-quan Lin (2006) [18] found that perceived organizational support consists of three dimensions, including job support, value recognition and interest. POS is influenced by a variety of factors, such as organizational rewards in the form of praise, money, promotions and influence, all given by the organization to employees as a way of communicating to employees that they are valued. 
POS has been associated with increases in affective commitment, positive mood, job satisfaction, loyalty, performance, and organizational citizenship behavior [19]. POS has also been associated with decreased turnover intentions and decreased job strain [20].

\subsection{Overview and Hypotheses}

According to the social exchange theory, exchanges recur over time, people always pursue the maximum benefit and seek the most powerful exchange object and activity. The relationship between organization and employees is also one kind of exchange relationship, which embodies the basic principles of social exchange theory. Social exchange theory not only looks at interpersonal interaction from the perspective of "cost-benefit", but also involves invisible social cost and benefit exchange, such as respect, honor, friendship and care, which do not follow external rules and agreements. Therefore, social exchange has no clear guarantee on whether the input cost can get reciprocal returns The only guarantee is the assumption of the exchange partner's cooperation intention, that is, the belief in the reciprocal cooperation of exchange partners, which is the core of social exchange theory [21]. Employees' responsibility and commitment to the enterprise is based on reciprocity. In the process of exchange, if the employee does not have this belief (that is, trust), his or her dependence on the enterprise will be reduced, and it is impossible to have affective commitment to the enterprise, and exptress positive work behavior and create high performance. It can be seen that employees' trust in the enterprise or management is very important to affective commitment.

In the relationship between employees and enterprises, both employees and enterprises have their power and expectation. Exchanges between organizations and employees should be mutually beneficial. Enterprises hope that employees work hard and get high performance. While employees not only expect to get remuneration, but also hope to get respect, friendship and pleasure from the enterprise in the process of labor. This is actually an unwritten psychological contract between employees and enterprises. Generally speaking, reliability is the starting point of building trust. Only when employees believe that the enterprise is willing and able to fulfill its commitment, can employees have confidence to trade with the enterprise, generate organizational commitment, and treat their work with more positive attitude. Therefore, in the daily management activities, managers should pass on the relevant information of capabilities through various communication channels, so as to enhance employees' rational cognition of enterprise capabilities. Organizational justice is actually a signal of trust to employees [22]. If an enterprise fulfills its promise as expected, treats its employees fairly, and meets their needs, then the employees will be motivated to form trust in the enterprise and be willing to establish affective interaction with the enterprise, employees will have affective commitment to the enterprise, regard the enterprise as their home, and spontaneously generate positive behaviors to improve their work performance. Thus, justice, POS and commitment are theoretically intertwined via social exchanges.

According to the organizational support theory, the establishment of employment relationship is the exchange of material benefits and social rewards by employees' hard work and loyalty. The organization's concern and attention to employees is an important reason for employees to stay in the organization and contribute to the organization. In order to meet socioemotional needs and to assess the benefits of increased work effort, employees form a general perception concerning the extent to which the organization values their contributions and cares about their well-being. Higher organizational support will make employees have strong affective commitment and a strong sense of obligation to the organization. Employees who feel lower organizational support are more likely to leave the organization. Organizational support meets the social emotional needs of employees. If employees feel that the organization is willing and able to repay their work, employees will make more efforts for the interests of the organization. If employees are given suitable respect and important value resources, they will have a sense of obligation and help the organization achieve its goals by increasing work performance according to the principle of reciprocity. On the contrary, if the organization ignores the needs of employees and lacks the support and care for employees, it will destroy the psychological contract of employees and generate low trust. We can see that perceived organizational support can transform employees' positive perception of organizational activities into obligation or emotional commitment, then affects employees' psychology and behavior. Along with improvement of perceived organizations support, employees would increase obligation to help the organization reach its objectives, and tend to develop positive perception and beliefs of organization and reward with higher affective commitment. Strong sense of organization support would be more likely to increase the satisfaction of psychological needs, make employees feel more highly related to the organization and its members. Perceived organizational support (POS) is usually used to signify the organization's care for its employees'welfare. Moreover, reciprocity obliges employees to return such attention, which can make employees invlove more attention on their job. Employees with high POS should avoid a high level of voluntary withdrawal behaviors, and instead engage in nonwork-related conversations. Consistent with the prior literature and results, this work predicts that POS is positively associated with affective commitment.

Organizational justice was found to be significantly and positively related to perceived organizational support. Affective commitment can be perceived as a reflection of work experiences. Individuals may become involved in their jobs in response to specific attributes of the work situation. As employees develop a better understanding and acceptance of organizational goals and values, conveyed through the organizational climate, they are likely to become more 
identified and involved with their job. Perception of distributive justice can lead to the tendency and attitude of employees to be involved, so as to improve the degree of affective commitment. Procedural justice can affect employees' attitudes and behaviors more than distributive justice; the employees have a sense of organizational support through constant experience of procedural justice. Thus organizational justice is one of the main factors involved in employee involvement.

Based on above description, the following hypotheses are generated in this study:

Hypothesis 1: Organizational justice is positively related to perceived organizational support.

Hypothesis 1a: distributive justice is positively related to perceived organizational support.

Hypothesis 1b: procedure justice is positively related to perceived organizational support.

Hypothesis 1c: interpersonal justice is positively related to perceived organizational support.

Hypothesis 1d: informational justice is positively related to perceived organizational support.

Hypothesis 2: oganizational justice is positively related to affective organizational commitment.

Hypothesis 2a: distributive justice is positively related to affective commitment.

Hypothesis $2 \mathrm{~b}$ : procedure justice is positively related to affective organizational commitment.

Hypothesis 2c: interpersonal justice is positively related to affective organizational commitment.

Hypothesis $2 \mathrm{~d}$ : informational justice is positively related to affective organizational commitment.

Hypothesis 3: POS is positively related to affective organizational commitment.

Hypothesis 4: POS plays a mediating role between organizational justice and affective organizational commitment.

\section{Method}

\subsection{Participants and Procedures}

The study took place in three local manufacturing companies. Questionaire were shared in work group by managers and 217 answered questionnaires were obtained. Participants had a median age range of 25-30 years and 53\% were men. The majority (72\%) was staff, $28 \%$ of the participants were middle-level managers. And the majority $(86 \%)$ had worked in the company for more than 2 years.

\subsection{Measures}

\subsubsection{Organizational Justice}

We measured organizational justice from the employee perspective using the 22-item scale from Ya Liu Li-rong Long and Ye Li (2003). Meta-analytical evidence has indicated that the scale provides the soundest psychometric properties and high reliability and validity. Organizational justice is defined as a four-dimension construct in the scale.
A1-A6 items measure distributive justice, A7-A12 items measure procedure justice, A13-A18 items measure leadership justice, A19- A22 items measure information justice. Employees answered on 5-point Likert-type scales with question-specific labels (for the sample item $1=$ not a bit to $5=$ a great deal). Cronbach's $\alpha$ was. 861 .

\subsubsection{Perceived Organizational Support}

We measured perceived organizational support with 17 items from a scale developed by Eisenberger et al.'s (1986). The scale perceived organizational support measures how much organization values the employees' contribution and cares about their well-being. A sample item was "The organization takes pride in my accomplishments at work". Items were answered on 5-point Likert-type scales ranging from $1=$ very little to $5=$ very much. Cronbach's $\alpha$ was. 921 .

\subsubsection{Affective Commitment}

The affective commitment questionnaire is derived from the three factor of organizational commitment questionnaire developed by Mayer and Allen in 1997, which describes three types of organizational commitment. Affective commitment measures an employee's emotional attachment, identity, and commitment to his organization. The original questionnaire consists of three parts, each part has 8 items. We adopts the affective commitment part. Items were rated on five-point Likert-type scales ranging from $1=$ never to $5=$ very often. Cronbach's $\alpha$ was. 918, which indicates acceptable internal reliability.

\section{Results}

The descriptive statistics for the variables in this study are presented in Table 1. The median and mean are similar to one another for the variables, suggesting that the variables were normally distributed. Pearson relationship analyses were performed to examine the relations among organizational justice, perceived organizational support and affective commitment. As shown in table 2, organizational justice, organizational support and affective commitment are significantly correlated at 0.01 level (bilateral), indicating that there is a significant positive correlation between organizational justice, organizational support and Affective Commitment. There is a significant positive correlation between each dimension of organizational justice and perceived organizational support. At the significance level of 0.01 , they all show clear correlation through statistical tests. There is a significant positive correlation between the four dimensions of organizational justice and affective commitment.

Regression analyses were performed to examine the relations between four dimensions of organizational justice and affective commitment. The results for the regression equations are presented in table 3. Distributive justice, procedural justice, leadership justice and information justice have a significant positive relationship with affective commitment. The regression coefficients in the columns estimate the magnitude of the effect of an independent 
variable on the dependent variable. For the affective commitment equation, leadership justice has the greatest

effect, followed by distributive justice.

Table 1. Descriptive statistics for study variables.

\begin{tabular}{lllll}
\hline variable & Min & Max & Mean & SD \\
\hline Distributive justice & 1.33 & 4.83 & 3.30 & .64 \\
Procidural justice & 1.17 & 4.67 & 3.28 & .68 \\
Leadership justice & 1.33 & 4.83 & 3.27 & .61 \\
Information justice & 1.25 & 5.00 & 3.23 & 3.27 \\
Organizational justice & 1.27 & 4.75 & 3.26 & .72 \\
Perceived organizational support & 1.25 & 5.00 & 3.29 & .62 \\
Affective Commitment & 1.25 & 4.88 & .69 & \\
\hline
\end{tabular}

Table 2. Pearson correlation matrix for study variables.

\begin{tabular}{|c|c|c|c|c|c|c|c|}
\hline variables & 1 & 2 & 3 & 4 & 5 & 6 & 7 \\
\hline D-justice & 1 & & & & & & \\
\hline P-justice & $.82^{* *}$ & 1 & & & & & \\
\hline L-justice & $.87^{* *}$ & $.84^{* *}$ & 1 & & & & \\
\hline I- justice & $.86^{* *}$ & $.80^{* *}$ & $.83^{* *}$ & 1 & & & \\
\hline O-justice & $.95^{* *}$ & $.92^{* *}$ & $.94^{* *}$ & $.94^{* *}$ & 1 & & \\
\hline Pos & $.88^{* *}$ & $.89^{* *}$ & $.89^{* *}$ & $.89^{* *}$ & $.95^{* *}$ & 1 & \\
\hline $\mathrm{AC}$ & $.74^{* *}$ & $.66^{* *}$ & $.77^{* *}$ & $.75^{* *}$ & $.79^{* *}$ & $.79^{* *}$ & 1 \\
\hline
\end{tabular}

Note. ${ }^{*} \mathrm{p} \leq .05{ }^{* *} \mathrm{p} \leq .01$.

Table 3. Regression analyses of 4 dimensions of organizational justice and Affective Commitment.

\begin{tabular}{|c|c|c|c|c|c|c|c|c|c|}
\hline \multirow{2}{*}{\multicolumn{2}{|c|}{ model }} & \multirow{2}{*}{ B } & \multirow{2}{*}{ Beta } & \multirow{2}{*}{$\begin{array}{l}\text { adjusted } \\
\text { R square }\end{array}$} & \multirow{2}{*}{$\mathbf{t}$} & \multirow{2}{*}{ Sig. } & & \multicolumn{2}{|c|}{ Collinearity statistics } \\
\hline & & & & & & & & Tolerance & VIF \\
\hline \multirow{2}{*}{1} & constant & .224 & .168 & & & 1.33 & .18 & & \\
\hline & Leadership justice & .95 & .05 & .77 & .59 & 18.87 & .00 & 1.00 & 1.00 \\
\hline \multirow{3}{*}{2} & constant & .22 & .16 & & & 1.39 & .16 & & \\
\hline & Leadership justice & .58 & .08 & .47 & .63 & 6.74 & .00 & .31 & 3.23 \\
\hline & Information justice & .38 & .07 & .36 & & 5.17 & .00 & .31 & 3.23 \\
\hline \multirow{4}{*}{3} & constant & .16 & .16 & & \multirow{4}{*}{.64} & .99 & .32 & & \\
\hline & Leadership justice & .45 & .10 & .36 & & 4.32 & .00 & .21 & 4.77 \\
\hline & Information justice & .28 & .08 & .27 & & 3.49 & .00 & .24 & 4.20 \\
\hline & Distributive justice & .23 & .10 & .20 & & 2.24 & .02 & .18 & 5.54 \\
\hline
\end{tabular}

Table 4. Correlation coefficient variation: POS as the control variable.

\begin{tabular}{|c|c|c|c|c|c|c|}
\hline variable & & Distributive justice & Procidural justice & Leadership justice & Information justice & POS \\
\hline Pre-control & Affective Commitment & $.759 * *$ & $.661 * *$ & $.772 * *$ & $.754 * *$ & $.785 * *$ \\
\hline After-control & Affective Commitment & .193 & -.187 & .226 & .170 & .152 \\
\hline
\end{tabular}

**. Significant correlation was found on the. 01 level (bilateral).

Table 5. Mediating effect test results of POS.

\begin{tabular}{|c|c|c|c|c|c|c|}
\hline \multirow{2}{*}{ model } & \multirow{2}{*}{ Unstandardized Coefficients } & \multirow{2}{*}{ Adjust the $R$ square } & \multirow{2}{*}{$\mathbf{t}$} & \multirow{2}{*}{ Sig. } & \multicolumn{2}{|c|}{ Collinearity statistics } \\
\hline & & & & & allowance & VIF \\
\hline (constant) & .35 & & 2.25 & .03 & & \\
\hline POS & .56 & .642 & 4.34 & .00 & .10 & 9.89 \\
\hline OJ & .35 & & 2.38 & .02 & .10 & 9.89 \\
\hline
\end{tabular}

The stepwise regression model was made by putting affective commitment as the dependent variable, organization justice and organizational support as the independent variable. Shown as in table 5, the estimated multiple regressions has reached the significance level as a whole; and the corresponding value of the $\mathrm{t}$ statistic is less than 0.05 , indicating that the single hypothesis test of the regression model coefficient also significant. After adding perceived organizational support, the regression coefficient of organizational justice and affective commitment fell from 0.785 to 0.288 , which mean that when POS exist, the impact of organization fairness on affective commitment would be weakened. These results demonstrate that the link to show mediation by POS was established.

\section{Discussion}

The predictive factors of affective organisational commitment has been tested by many studies. However, little attention has been paid to its linkages with employees' organizational justice, and research on mediators in the relationship between affective organisational commitment, 
perceived organizational support and organizational justice is scarce. The current study addressed these limitations of the literature. Analyses showed that organisational justice and perceived organiational support predicted affective commitment. From the perspective of social exchange theory, the more procedural justice that are accumulated, the greater the feeling of indebtedness to the organisation, which employees may be morally obligated to repay through affective commitment. When frontline employees perceive that their organisations and managers are willing to treat them farily and respect for their efforts, they are likely to manifest higher affective commitment. These findings support the above hypotheses and suggest that individual perception of the organizational support plays a role in understanding when and why employees pay high attention to their work and invest more effort to achieve organizational goals.

\section{Conclusion}

This study aimed to broaden knowledge on the organisational justice-affective commitment by examining possible mediators. First it was found that organisational justice and its dimensions predict affective organizational commitment. The present study further confirmed that perceived organizational support mediate the relationship of organisational justice and its dimensions with affective commitment. The results concur with the perspective of social exchange theory that employees treated fairly and receives resources from the organization in which they work are more likely to reciprocate with positive attitudes. Fair and supportive organizational policies and procedures can cultivate employees' affective commitment to their organization. The findings further suggest that managers can improve individual employee's commitment by creating more justice and consistently supportive organizational policies. As research on job attitude and behaviour continues to develop, we hope that our research might stimulate further inquiries into the role of contextual factors in the work behavior relationship.

\section{Acknowledgements}

The authors would like to thank National Natural Fund under Contract Nos. 71971003.

\section{References}

[1] Arsalan Mujahid Ghouri, Pervaiz Akhtar, Muhamma Shahbaz, Haseeb Shabbir. "Affective organizational commitment in global strategic partnerships: The role of individual-level microfoundations and social change." Technological Forecasting \& Social Change, 2019, vol. 146, pp. 320-330.

[2] Marie-Claude Gaudet, Michel Tremblay. "Initiating structure leadership and employee behaviors: The role of perceived organizational support, affective commitment and leaderemember exchange," European Management Journal, 2017, vol. 35, pp. 663-675.
[3] Tayyaba Akram, Shen Lei, Muhammad Jamal Haider, Syed Talib Hussain. "The impact of organizational justice on employee innovative work behavior: Mediating role of knowledge sharing," Journal of Innovation \& Knowledge, 2020, vol. 5, pp. 117-129.

[4] Nianlong Luo, Xunhua Guo, Benjiang Lu, Guoqing Chen. "Can non-work-related social media use benefit the company? A study on corporate blogging and affective organizational commitment," Computers in Human Behavior, 2018, vol. 81 pp. 84-92.

[5] Simone Donati, Salvatore Zappala, Vicente Gonzalez-Rom. "The double-edge sword effect of interorganizational trust on involvement in interorganizational networks: The mediator role of affective commitment," European Management Journal, 2020, vol. 38, pp. 613-622.

[6] Kuruüzüm, A., Cetin, E. I., \& Irmak, S., "Path analysis of organizational commitment, job involvement and job satisfaction in the Turkish hospitality industry," Tourism Review, 2009. vol. 64 pp. 4-16.

[7] Zhengzheng Lin, Zhongyun Zhou, Yulin Fang, Doug Vogel, iang Liang, "Understanding affective commitment in social virtual worlds: The role ofcultural tightness," Information \& Management, 2018, vol. 55, pp. 984-1004.

[8] Ji Wen, Songshan (Sam) Huang, Pingping Hou. "Emotional intelligence, emotional labor, perceived organizational support, and job satisfaction: A moderated mediation model," International Journal of Hospitality Management, 2019. vol. 81 pp. $120-130$.

[9] Emmanuel Twumasi Ampofo, "Mediation effects of job satisfaction and work engagement on the relationship between organisational embeddedness and affective commitment among frontline employees of star-rated hotels in Accra," Journal of Hospitality and Tourism Management, 2020. vol. 44 pp. 253-262.

[10] Nabatchi, T., Bingham, L., \& Good, D. H., "Organizational justice and workplace mediation: A six factor model," International Journal of Conflict Management, (2007) 18 (2), $148-174$.

[11] Yu Cui, Hao Jiao, "Organizational justice and management trustworthiness during or ganizational Change: Interactions of Benevolence, Integrity, and managerial approaches," Information Processing and Management, 2019, vol. 56, pp. $1526-1542$.

[12] Meriem Bouazzaoui, Hung-Jui Wu, Jens K. Roehrich, Brian Squire, Anthony S. Roath., "Justice in inter-organizational relationships: A literature review and future research agenda," Industrial Marketing Management, 2020. vol. 87, pp. 128-137.

[13] Bies, R., \& Moag, J., "Interactional justice: Communication criteria of fairness," In R. (1986).

[14] Greenberg, J., "Stealing in the name of justice: Informational and interpersonal moderators of theft reactions to underpayment inequity," Organizational Behavior and Human Decision Processes, (1993) 54, 81-103.

[15] Colquitt, J., Scott, B., Rodell, J., Long, D., Zapata, C., Conlon, D., et al., "Justice at a millennium, a decade later: A meta-analytic test of social exchange and affect-based perspectives," Journal of Applied Psychology, (2013) 98 (2), 199-236. 
[16] Chong-ming Wang., Management psychology. Beijing: People's education Press. (2001).

[17] Pascal Paille, Jorge H., Meija-Morelos. "Organisational support is not always enough to encourage employee environmental performance: The moderating role of exchange ideology," Journal of Cleaner Production, 2019, vol. 220, pp. 1061-1070.

[18] Wen-quan Lin, Hai-jun Yang, Li-luo Fang., "Employee 's organizational support," Journal of Psychology, 2006, vol. 2, pp. 281-287.

[19] Rubenstein, A. L., Allen, D. G., \& Bosco, F. A., "What's past (and present) is prologue: Interactions between justice levels and trajectories predicting behavioral reciprocity," Journal of Management, 2019, vol. 45, pp. 1569-1594.
[20] Fortin, M., Cojuharenco, I., Patient, D., \& German, H., "It is time for justice: How time changes what we know about justice judgments and justice effects," Journal of Organizational Behavior, 2016. vol. 37, pp. S30-S56.

[21] Su Jin Kim, Eun Kyoung Chung, "The effect of organizational justice as perceived by occupational drivers on traffic accidents: Mediating effects of job satisfaction," Journal of Safety Research, 2019. vol. 68, pp. 27-32.

[22] Soundararajan, V., \& Brammer, S., "Developing country sub-supplier responses tosocial sustainability requirements of intermediaries: Exploring the influence off raming on fairness perceptions and reciprocity," Journal of Operations Management, 2018, vol 58, pp. 42-58. 